\title{
Contracampo
}

\section{Twitter e esfera pública: pluralidade e representação na discussão sobre o Marco Civil da internet ${ }^{1}$}

\section{Twitter and public sphere: plurality and representation in the discussion of the Brazilian Civil Rights Framework for the internet}

\section{Letícia Varela Capone \\ leticiacapone@gmail.com}

Mestre em Comunicação Social pelo Departamento de Comunicação Social da Pontifícia Universidade Católica do Rio de Janeiro (PUC-RJ).

Arthur Ituassu ituassu@puc-rio.br

Professor do Programa de Pós-Graduação em Comunicação Social (PPGCOM) do Departamento de Comunicação Social da PUC-RJ e pesquisador no Centro de Estudos Avançados em Democracia Digital (CEADD), na Universidade Federal da Bahia (UFBA).

${ }^{1}$ Uma versão deste trabalho foi apresentada ao Grupo de Trabalho Comunicação e Sociedade Civil do VI Congresso da Associação Brasileira de Pesquisadores em Comunicação e Política (VI COMPOLíTICA), na Pontifícia Universidade Católica do Rio de Janeiro (PUC-RJ), de 22 a 24 de abril de 2015. Os autores agradecem as contribuições sugeridas pelos colegas durante a discussão da pesquisa.

Ao citar este artigo, utilize a seguinte referência bibliográfica

CAPONE, Letícia Varela, ITUASSU, Arthur. Twitter e esfera pública: pluralidade e representação na discussão sobre o Marco Civil da internet. In: Revista Contracampo, v. 33, n. 2, ed. ago-nov, ano 2015. Niterói: Contracampo, 2015. Págs: 86-108.

DOI: $10.5327 / Z 22382577201500332783$

Enviado em: 19 de jun. de 2015

Aceito em: 15 de set. de 2015

\section{PPGCOM}

Contracampo

Niterói (RJ), v. 33, n. 2, ago-nov/2015

www.uff.br/contracampo

A Revista Contracampo é uma revista eletrônica do Programa de PósGraduação em Comunicação da Universidade Federal Fluminense e tem como objetivo contribuir para a reflexão crítica em torno do campo midiático, atuando como espaço de circulação da pesquisa e do pensamento acadêmico. 


\section{Resumo}

Esta é uma pesquisa no campo da Internet e Democracia que dialoga com os estudos que analisam as contribuições da Web para a esfera pública nos regimes democráticos contemporâneos. Nesse contexto, tem como tema a discussão no Twitter sobre o Marco Civil da internet, com o objetivo de perceber quais foram as grandes polêmicas, quão plural foi o debate e que tipo de mídia esteve presente no espaço especificado para análise. Com base em métodos quantitativos e qualitativos, aplicados sobre uma amostra relevante de 388 tweets, foi constatado um predomínio de vozes especialistas, bem como um grande compartilhamento de conteúdo produzido por mídias horizontais, que dominaram a discussão.

Palavras-chave: Marco Civil da internet; Twitter; representação.

\section{Abstract}

This is a research in the field of Internet and Democracy that dialogues with the studies that analyze Web contributions to the public sphere of contemporary democratic regimes. The intention was to analyze the discussion on Twitter about the Brazilian Civil Rights Framework for the internet, in order to observe which were the major controversies, how plural was the debate and what kind of media (horizontal or vertical) was present in the specified space. Based on qualitative and quantitative analysis of the object, 388 tweets, we found a prevalence of expert voices, as well as a large share of content produced by horizontal media.

Keywords: Brazilian Civil Rights Framework for the internet; Twitter; representation. 


\section{Introdução}

sta é uma pesquisa no campo da Internet e Democracia que dialoga com os estudos
que analisam as contribuições da $W e b$ para a esfera pública nos regimes democráticos contemporâneos (GOMES; MAIA, 2008; DAHLGREN, 2005; BOHMAN, 2004; CHADWICK, 2009). Nesse contexto, tem como tema a discussão no Twitter sobre o Marco Civil da Internet, com o objetivo de perceber como se deu o debate sobre o assunto nessa mídia social, como: quais foram as grandes polêmicas, quão plural foi a "conversa" (CAREY, 1989) e que tipo de mídia horizontal ou vertical (SHAW et al., 2006) esteve presente no espaço especificado para análise.

O Marco Civil da Internet foi uma iniciativa do Ministério da Justiça, que, em 2009, motivado pela reação negativa da sociedade civil ao Projeto de Lei 84/1999, chamado, na Web, de "AI5 Digital", iniciou um processo de consulta pública para a produção de uma lei que versasse sobre direitos e responsabilidades na internet (BRAGATTO et al., 2014, p. 2). Foram realizadas duas Consultas Públicas, em 2009 e em 2010, que resultaram em um projeto encaminhado pela presidente Dilma Rousseff, em agosto de 2011, à Câmara dos Deputados. Após uma longa batalha política, o Projeto de Lei em questão foi aprovado pelos Deputados Federais em março de 2014 e, em abril deste mesmo ano, pelo Senado Federal. A presidente Dilma sancionou a lei logo em seguida e o Marco Civil da Internet, neste momento, passa pela fase de construção de sua regulamentação.

Para testar, empiricamente, os aspectos representacionais que envolveram a discussão em torno do Marco Civil da Internet no Twitter, no que diz respeito à pluralidade de vozes presentes no debate, selecionamos como recorte inicial os dias 29 de outubro de 2009, data de início da primeira consulta pública, e 30 de outubro de 2009, a fim de desvendar os desdobramentos da "conversa" no dia seguinte. Compuseram o corpus dessa pesquisa os 388 tweets postados nos dois dias mencionados acima que continham a hashtag \#marcocivil. Esses dados foram analisados de acordo com as vozes representadas, as mídias compartilhadas e os temas abordados.

Realizada a pesquisa, constatamos que a discussão ocorrida no Twitter, ao menos no período estipulado e no plano delimitado da hashtag, não parece trazer uma contribuição expressiva no que diz respeito à variedade de participantes na "conversa", marcada pela especialização e complexidade do tema, mas, sim, com relação à variedade das fontes, com a contribuição de mídias horizontais, que dominaram o espaço de visibilidade naquele momento. 
Sendo assim, este trabalho está dividido em mais quatro seções além desta introdutória. Na seguinte, está uma breve discussão teórica que serve de referência para a análise sobre os potenciais que a internet traz para a esfera pública, levando em consideração seus aspectos representacionais (DAHLGREN, 2005) e aproximando-se da noção de interação continuada, que insere as discussões em um contexto cultural mais abrangente (MAIA, 2008, p. 289). Na terceira e quarta seções estão, respectivamente, a metodologia utilizada e os resultados da pesquisa empírica. Na discussão final, enfatizamos que, no debate em torno do Marco Civil da Internet no Twitter, no recorte estipulado, predominaram vozes especializadas no tema, muitas vezes de um mesmo usuário com alto índice de postagens — os superposters (GRAHAM; WRIGHT, 2013) - e fontes, em sua maioria, mais de nicho, de caráter mais complementar à mídia de mainstream.

\section{Esfera pública no ambiente digital: potenciais e fragilidades}

Esta seção tem por objetivo desenvolver uma discussão teórica de modo a constituir uma hipótese de trabalho, a ser testada empiricamente, acerca das contribuições da Web para a esfera pública nos regimes democráticos contemporâneos. Para tanto, irá analisar, em primeiro lugar, a própria noção de esfera pública e seu lócus na teoria mais recente da democracia. Em seguida, discutirá as potenciais contribuições da $W e b$, apontadas pela literatura, para, ao fim, apresentar alguns limites e problemas impostos a essa mesma discussão.

Nesse sentido, a partir da sugestão de Dahlgren (2005) sobre as três dimensões constitutivas da esfera pública - estrutural, representacional e interacional —, a intenção aqui é desenvolver uma análise no plano da segunda dimensão, que, segundo o próprio autor, abrange:

1. a produção dos meios de comunicação, inclusive a internet;

2. o espaço de visibilidade midiática; e

3. a acuidade, a precisão, a completude e a pluralidade de vozes e agendas presentes nas informações veiculadas e nos debates estabelecidos (DAHLGREN, 2005, p. 148-149).

Mas antes de lidar com as questões representacionais, é necessário, primeiramente, a nosso ver, traçar um panorama da discussão que envolve a esfera pública e o ambiente digital. 
Nesse sentido, é importante perceber que o advento da internet trouxe uma enorme expectativa de grandes mudanças no cenário político comunicacional. Atributos e potenciais da $W e b$, como a possibilidade do acesso universal, a comunicação não-coercitiva ou hierarquizada e a liberdade de expressão (GOMES, 2008, p. 304-305), potencializaram noções como a de um novo ambiente de deliberação, um novo e importante "lugar", ou "arena conversacional", na qual o espaço se desdobra e novas conversações e discussões políticas podem seguir seu curso" (MAIA, 2008, p. 283). De acordo com Castells (2003, p. 135), as novas tecnologias teriam o potencial de transformar a dimensão política, tornando-se o espaço propício para que os cidadãos expressem seus direitos e se comuniquem com outros, compartilhando valores e questões. A possibilidade de se ter um público ampliado também é uma das vantagens apontadas pelos que enxergam a internet com potencial de renovar a prática deliberativa: o diálogo e a troca de argumentos prescindem dos encontros face a face, transcendendo as fronteiras do Estado-nação para uma participação em escala global, expandindo os fóruns conversacionais (MAIA, 2008, p. 283).

Nesse contexto, Gerards e Schäfer (2010, p. 3) reiteram as expectativas que a internet traz de inclusão de múltiplos atores aos debates, especialmente aqueles da sociedade civil que não têm acesso ao espaço da visibilidade midiática. Para os autores, a Web teria o potencial de trazer interpretações alternativas, servindo como um impulso para a democratização da esfera pública, para o fortalecimento do interesse pelos aspectos políticos e para a participação cidadã. Da mesma forma, segundo Maia (2008, p. 286-287), o ambiente digital pode ser vantajoso para o debate crítico-racional, uma vez que é um espaço livre de coerções e onde usuários têm possibilidades de se associar e se engajar em diferentes causas, fóruns e comunidades virtuais. Além disso, há uma relação dialógica estabelecida, em que interlocutores podem prescindir da presença física e do diálogo em tempo real e realizar trocas irrestritas de ideias, numa comunicação multidirigida, sem que haja a necessidade de se manter parceiros fixos ou autorizados. Vale sinalizar, ainda, que livres dos encontros face a face e munidos do anonimato propiciado pelas redes, cidadãos podem estabelecer diálogos e debates de forma mais paritária, uma vez que, diante desde quadro, as desigualdades sociais sofrem um relativo apagamento. Como afirma a autora "[s]e a discussão acontece em um ambiente livre de medo, de intimidação ou de ridículo, uma variedade maior de pontos de vista pode ser expressa" (MAIA, 2008, p. 287). 
Há, porém, as fragilidades que dizem respeito ao uso das redes, como um elevado número de participantes de discussões online que, embora registre sua opinião ou busque informações, não se vincula ao debate contínuo, reduzindo a prática argumentativa (MAIA, 2008, p. 288). Alguns autores (FRASER, 2007; GOLDBERG, 2011) também ressaltam problemas de legitimidade e eficácia. O primeiro ponto indica uma questão de inclusividade, particularmente no que diz respeito a grupos historicamente excluídos das instituições de poder, e a segunda ressalta a inabilidade dos cidadãos de comunicarem suas demandas e desejos às instituições, bem como das instituições de ouvirem e, quiçá, atenderem as reivindicações. Nesse contexto, de acordo com a obra de Benkler (2006), mencionada por Goldberg (2011, p. 742), as críticas à esfera pública virtual podem ser divididas nas seguintes categorias: a questão babélica — isto é, a internet percebida como um ambiente sobrecarregado de informações, o que gera a fragmentação, a polarização do discurso e a perda da comunidade política; a questão da potência — já que poucos sites detêm a maior parte do tráfego; o controle ao acesso à informação pelos estados autoritários; e, por fim, o digital divide — isto é, a exclusão de parte dos cidadãos das redes digitais.

Nessa mesma linha, Neuman (2001, p. 304) salienta quatro conceitos que envolvem a esfera pública, a distribuição de informação política e os valores e comportamentos: a coesão social, que abarca as leis, a ordem, as normas sociais, normalmente conservadoras, e a preocupação legítima e prática, não ideológica, do processo democrático nas sociedades industriais e desenvolvidas; a fragmentação, que seria a distribuição horizontal de crenças e preferências em uma sociedade, de acordo com as diferentes comunidades regionais, étnicas e ideológicas, resultando na dispersão de valores; a estratificação, que engloba as diferenças verticais entre elites e massas no que diz respeito às informações políticas; e, por fim, a polarização, envolvendo não somente a distribuição de crenças e opiniões, mas a atuação frente às diferenças sociais e comportamentais percebidas. De acordo com o autor, a redução de custos em se adquirir e em disponibilizar informações políticas na internet pode significar, em algum grau, um aumento da participação do cidadão na esfera política, mas não altera nem iguala, em larga escala, os níveis de polarização e estratificação das crenças e opiniões políticas (NEUMAN, 2001, p. 317).

Ambas as posições com relação ao potencial da internet de incremento da esfera pública, no entanto, são relativizadas quando tomamos a $W e b$ e os processos de deliberação não somente como encontro dialógico singular, em busca de uma decisão conjunta 
prática e profícua, mas tendo a noção de espaços de interação continuada, inserindo as discussões num contexto cultural mais abrangente, ligadas à formação de preferências e de convicções. Além disso, o processo continuado de deliberação pode significar uma forma de aprendizagem, já que, durante os debates, os cidadãos podem se tornar mais críticos a respeito dos temas expostos e, até mesmo, das próprias opiniões, podendo, ainda, diante dos processos deliberativos, mudar suas atitudes e orientações políticas e encorajar-se a apresentar suas ideias (MAIA, 2008, p. 289-290).

Maia (2008, p. 291-292), nesse contexto, diferencia o discurso singular, que objetiva a obtenção de uma decisão obrigatória e final, exigindo que os participantes destes tipos de debate sejam altamente comprometidos e engajados, do discurso prático, processo comunicativo mais reflexivo que ocorre com maior ou menos intensidade em nossas vidas. Assim como um processo gradual e disperso, sempre aberto à revisão, o debate público pode acarretar numa interpretação coletiva e entendimento mútuo dos interesses mais importantes, a respeito da vida comum dos cidadãos. Sendo assim, a deliberação pode servir a diversos fins e pode ser questionável a tentativa de limitá-la (e enquadrá-la) a um processo com um único objetivo principal (SAMPAIO et al., 2012).

Em consonância com a ideia de deliberação continuada proposta por Maia, a concepção de esfera pública para Dahlgren (2005, p. 148) passa pela circulação de informações, ideias, debates e pela formação da vontade política, todos estes aspectos facilitados e propiciados pelos meios de comunicação de massa e, mais recentemente, pela internet. $\mathrm{O}$ autor indica que, diferentemente da ideia inicial de Habermas, a esfera pública não obedece a uma forma única e singular, mas à constituição de diferentes espaços e arenas, especialmente levando-se em consideração a complexidade das sociedades contemporâneas e os efeitos do mundo globalizado. De acordo com Dahlgren (2005, p. 152), a visão integrada, normativa e idealizada de esfera pública fracassou nas sociedades contemporâneas, que passam a se preocupar e a abarcar a pluralidade e as diferenças. Compõem as democracias atuais grupos de diferentes gêneros, etnia, capital cultural, orientação política que podem requerer espaços especializados de discussão, para trabalhar questões internas ou formar uma identidade coletiva.

Dahlgren (2005, p. 148-149) propõe, então, três dimensões constitutivas da esfera pública: estrutural, representacional e interacional. A primeira diz respeito aos aspectos formais e institucionais que permeiam um processo deliberativo, incluindo a liberdade de 
expressão, o acesso e a dinâmica inclusão/exclusão. Tanto a mídia quanto as instituições políticas formam uma ecologia política que também forma e estrutura a esfera pública e a maneira como a informação circula. A segunda dimensão, a representacional, mais cara a este trabalho, refere-se às vozes presentes na esfera pública, considerando que estas devem ser plurais, comportando variadas agendas, posições e ideias, e abrange:

1. a produção dos meios de comunicação, inclusive a internet;

2. o espaço de visibilidade midiática; e

3. a acuidade, a precisão, a completude e a pluralidade de vozes e agendas presentes nas informações veiculadas e nos debates estabelecidos (DAHLGREN, 2005, p. 148-149), como vimos acima.

Nesse caso, a mídia assume um papel central como espaço de visibilidade e de disseminação de informações. É justamente neste aspecto, o representacional, que nossa pesquisa se localiza, na tentativa de mapear que vozes estão representadas no debate sobre o Marco Civil da Internet no Twitter. A terceira e última dimensão, interacional, requer não simplesmente um público passivo e atomizado, mas cidadãos interagindo uns com os outros, premissa fundamental para que os processos deliberativos ocorram. Essa interação ocorre tanto no encontro de cidadãos com a mídia, uma vez que o usuário interpreta e usa os conteúdos veiculados nos meios de comunicação de massa, quanto na relação entre cidadãos, que engloba tanto uma conversa entre duas pessoas, quanto encontros maiores em escala, ou seja a comunicação em espaços da vida social.

\section{Metodologia}

A partir desse ponto, o objetivo desta pesquisa é testar empiricamente que vozes e temas estiveram presentes no debate desenvolvido no Twitter sobre o Marco Civil da Internet durante o período em que a iniciativa foi pauta institucionalizada da política brasileira, desde a primeira consulta pública sobre o tema, em outubro de 2009, até o momento em que a lei foi aprovada no Senado Federal, em abril de 2014.

Dessa forma, foram material de análise os tweets publicados com a hashtag \#marcocivil (a principal entre aquelas utilizadas) entre 29 de outubro de 2009 e 22 de 
abril de 2014. A escolha pelo mapeamento de hashtag, nesta pesquisa, se justifica pela tentativa de encontrar diferentes mensagens de diferentes usuários que versassem sobre um assunto específico (MARQUES; SILVA; MATOS, 2013), delimitando um espaço de conversação (ITUASSU; LIFSCHITZ, 2015). Além disso, o próprio blog oficial de discussão do Marco Civil da Internet, localizado na plataforma Cultura Digital, vinculada ao Ministério da Cultura, indicava no canto superior direito o ícone “\#marcocivil no Twitter". Como o " $n$ " potencial dessa pesquisa é enorme, mapeamos, nesse primeiro momento, as postagens da primeira fase de consulta pública sobre o Marco Civil da Internet, que ocorreu entre 29 de outubro de 2009 e 17 de dezembro de 2009. Nessa primeira fase da pesquisa, foram coletados os tweets postados na data principal do evento em questão, além daqueles publicados no dia posterior, a fim de verificar a repercussão e a amplitude do assunto Marco Civil da Internet no universo estabelecido para análise.

Com isso, o primeiro passo metodológico foi desenvolver uma busca, pela ferramenta Advanced Search (Pesquisa avançada, em tradução livre) do Twitter, de todos os tweets publicados com a marca \#marcocivil no período determinado, isto é, dias 29 e 30 de outubro de 2009. Os dados obtidos foram organizados em uma tabela com:

1. informações de identificação (nome do perfil);

2. data e hora da publicação;

3. texto do tweet;

4. qualidade da voz em questão e sua relação com a área;

5. tema da publicação; e, por fim,

6. tipologia da mídia replicada quando assim ocorreu, sendo as mídias classificadas como: mídia mais vertical (MV), mídia mais horizontal (MH) e nenhuma mídia ou nenhuma delas (NDA).

Coletados e organizados os 388 tweets, analisamos o material, tendo em vista dois eixos principais. O primeiro deles englobou a verificação e o mapeamento da qualidade das fontes que estabeleceram o diálogo em torno do tema Marco Civil da Internet pela sua "posição social ou organizacional" (cidadão, político, jornalista, mídia, etc.). Para tal, foram consideradas as fontes primárias, ou seja, quem publicou o tweet original. No intuito de obter o mapeamento da qualidade de cada voz, levou-se em consideração a descrição disponibilizada pelo próprio usuário em sua "bio" (pequena descrição do usuário) do Twitter 
e, quando não havia nenhuma informação deste tipo disponível, foi realizada uma busca em outras redes sociais que indicassem a atividade desempenhada pela fonte em questão. Foi levantada, ainda, a afinidade do usuário com o tema da discussão, isto é, a criação de um Marco Civil para a Internet, sendo estes classificados como vozes especializadas, caso de estudantes, advogados, ativistas, professores, entre outros, que detinham conhecimento em temas relacionados, tais quais, legislação para a internet; mídia e tecnologia; cibercultura; sistemas de informação; softwares livres, etc.; vozes não especializadas, quando o campo de atuação e interesse do usuário não englobava temáticas afins; e, por fim, NDA, quando nenhuma informação sobre o usuário foi localizada.

Por exemplo, um dos usuários informa no descritor de sua "bio" no Twitter que é professor de uma Universidade estadual. Em uma busca mais detalhada, percebemos que, além de lecionar a matéria Direito da Tecnologia da Informação, ele é diretor do Instituto de Tecnologia e Sociedade de um determinado estado. Sendo assim, o consideramos uma voz especializada. Outro usuário, também considerado especialista, diz ser, em sua "bio", cyberlawyer, informação confirmada em seu site, disponibilizado em seu Twitter. Em alguns casos foi possível identificar a área de atuação (e/ou interesse) dos usuários, sem que estas fossem relacionadas ao tema, como é o caso de um dos perfis que se descreve, na "bio" do Twitter, como cantor e compositor. Já em outras situações, os usuários não incluíam em sua "bio" nenhuma informação que nos levasse a sua posição social, também não sendo possível determiná-la em uma busca em outros sites e redes sociais. Sendo assim, consideramos estes como usuários indefinidos.

O outro eixo comportou a análise do texto de cada tweet, tendo em vista, primeiramente, o tema disposto em cada postagem e a qualidade do link (caso houvesse) que acompanhou a publicação, tendo em vista a definição de mídia vertical e horizontal apresentada por SHAW et al. (2006) e já utilizada em outra pesquisa (ITUASSU; LIFSCHITZ, 2015). Para determinar o tema, observamos sobre o que versou o tweet. Essa classificação pode ser melhor compreendida, por exemplo, com a postagem de @usuário11', que tinha como texto "Agora o Ministro da Justiça Tarso Genro fala no lançamento do \#marcocivil". O post se

A identidade dos usuários foi preservada para manter a privacidade dos mesmos, sendo estes chamados de @usuario1; @usuario2; e assim em diante. 
referia ao Evento de lançamento do Marco Civil da Internet, realizado na Fundação Getúlio Vargas (FGV), na ocasião de sua Primeira Consulta Pública. Já o tweet “Argumentos toscos! NÃO AO AI5Digital!! \#MarcoCivil da internet!! RT @usuário31: Azeredo fala sobre Ai5-Digital ... - http://j.mp/oAv5Fr”, postado por @usuário32, abordou a Lei de Azeredo, com a indicação de uma entrevista concedida pelo Deputado Federal Eduardo Azeredo (PSDB) ao Portal Terra. Um outro exemplo é o post de @usuário33 “Participe do \#marcocivil: acesse "Consulta" em http://bit.ly/49CwL5, escolha um tópico e clique em "Participar dessa discussão", ou seja, uma chamada para que os usuários participassem da discussão, com esclarecimentos sobre como fazê-lo.

Sobre os links de referência publicados em alguns tweets, quando as mídias de referência eram aquelas que apresentavam um fluxo de informação top down, dirigido a audiências mais gerais, como é o caso do portal Terra e Uol, ou das Revistas Época e Exame, as mesmas foram consideradas mídias mais verticalizadas. Já as mídias de nicho ou de conteúdo produzido por indivíduos ou organizações sociais específicos, que são mais próximas do status social do cidadão, se colocando, inclusive, em uma relação mais horizontal com o mesmo, como é o caso do site e do blog do Marco Civil da Internet; do blog do Josias da Folha de São Paulo; do site da Câmara dos Deputados, foram classificadas como mídia mais horizontais (ITUASSU; LIFSCHITZ, 2015).

\section{Análise e resultados}

Na ocasião da Primeira Consulta Pública, que ocorreu de 29 de outubro a 17 de dezembro de 2009, selecionamos como recorte, para a viabilidade da pesquisa, o dia de início e o posterior (29 e 30 de outubro de 2009). Foram 388 tweets no período, sendo 299 das postagens feitas por usuários especializados no tema; 48 por usuários não especializados; e 41 por usuários sem definição possível sobre o grau de especialização (NDA). Em termos percentuais, $77 \%$ dos tweets tiveram a autoria de vozes especializadas; $12 \%$ de não especializadas; e 11\% de usuários sem definição possível (NDA), conforme disposto no Gráfico 1.

Ao mapearmos as 48 postagens de usuários não especializados no tema, ou seja, aqueles que não tinham algum grau de expertise sobre o assunto, com o intuito de obter a qualidade de 


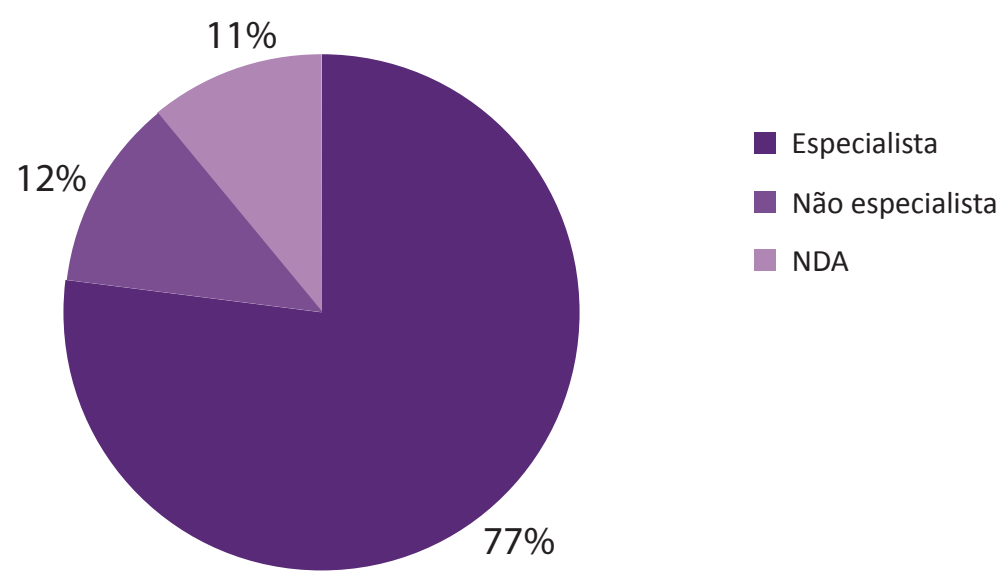

Gráfico 1. Número de tweets versus especialização na área ( $\mathrm{n}=388$ tweets)

cada voz, foi possível perceber um predomínio de postagens de mídias horizontais, jornalistas e professores. Na Tabela 1, estão indicadas todas as posições sociais e organizacionais das vozes não especializadas representadas no debate, num universo de 48 posts:

É possível perceber, pelos dados dispostos na Tabela 1, que houve uma predominância de determinadas qualidades de vozes no debate. Se considerarmos as dez primeiras posições de falantes, constatamos que, dentro do universo dos 48 tweets de não especialistas, 35 (ou 70\% das postagens) foram realizadas por eles. Ao aplicarmos um percentual para cada uma das dez principais vozes não especializadas dentro do universo total de tweets e dentro do universo de tweets da categoria, obtivemos os dados que podem ser observados na Tabela 2.

Sobre o mapeamento de vozes dos usuários especializados no tema, isto é, aqueles que possuíam expertise em áreas relacionadas ao Marco Civil da Internet, percebemos, nesse primeiro recorte temporal, uma predominância de postagens, respectivamente, do Twitter oficial do Marco Civil da Internet, de mídias horizontais, de organizações sociais, de ciberativistas e de ativistas. Na Tabela 3, está mapeada a qualidade das vozes dos usuários especializados, num universo de 299 posts.

Notamos, novamente, a predominância de determinadas qualidades de vozes: dos 299 tweets postados por especialistas, $83 \%$ (ou 247) são de autoria das dez primeiras mapeadas. Entre os tweets totais, ou seja, os 388 , as 10 vozes especialistas mais falantes foram responsáveis por mais da metade das postagens (64\%). Na Tabela 4, consta a representatividade percentual 
Tabela 1. Mapeamento da qualificação das vozes não especializadas

\begin{tabular}{ll} 
& Qualificação das vozes não especializadas \\
\hline Qualidade da voz & Número de tweets \\
Mídia horizontal & 9 \\
\hline Jornalista & 5 \\
\hline Professor & 5 \\
\hline Cantor & 3 \\
\hline Empresa & 3 \\
\hline Pesquisador & 3 \\
\hline Organização social & 2 \\
\hline Partido & 2 \\
\hline Político & 2 \\
\hline Analista contábil & 1 \\
\hline Analista de comunicação & 1 \\
\hline Assessor de comunicação & 1 \\
\hline Consultor & 1 \\
\hline Diretor de criação & 1 \\
\hline Escritor & 1 \\
\hline Estudante & 1 \\
\hline Físico & 1 \\
\hline Fotógrafo & 1 \\
\hline Advogado & 1 \\
\hline Musico & 1 \\
\hline Profissional de logística & 1 \\
\hline Redator & 1 \\
\hline Roteirista & 1 \\
\hline
\end{tabular}

Tabela 2. Representação percentual das principais vozes não especializadas

\begin{tabular}{l|c|c|c}
\hline Qualidade da voz & Número de tweets & \% dos tweets totais (388) & \% dos tweets na área (48) \\
\hline Mídia horizontal & 9 & $2 \%$ & $19 \%$ \\
\hline Jornalista & 5 & $1 \%$ & $10 \%$ \\
\hline Professor & 5 & $1 \%$ & $10 \%$ \\
\hline Cantor & 3 & $1 \%$ & $6 \%$ \\
\hline Empresa & 3 & $1 \%$ & $6 \%$ \\
\hline Pesquisador & 3 & $1 \%$ & $6 \%$ \\
\hline Organização social & 2 & $1 \%$ & $4 \%$ \\
\hline Partido & 2 & $1 \%$ & $4 \%$ \\
\hline Político & 2 & $1 \%$ & $4 \%$ \\
\hline Advogado & 1 & $1 \%$ & $2 \%$
\end{tabular}


Tabela 3. Mapeamento da qualificação das vozes especializadas

\begin{tabular}{ll}
\multicolumn{1}{c}{ Qualificação das vozes especializadas } \\
\hline \multicolumn{1}{c}{ Qualidade da voz } & Número de tweets \\
Twitter oficial do MCl & 51 \\
\hline Mídia Horizontal & 42 \\
\hline Ciberativista & 29 \\
\hline Organização social & 26 \\
\hline Professor & 23 \\
\hline Ativista & 20 \\
\hline Analista de sistemas & 18 \\
\hline Empreendedor & 15 \\
\hline Jornalista & 13 \\
\hline Mídia Vertical & 10 \\
\hline Servidor & 9 \\
\hline Advogado & 7 \\
\hline Governo & 6 \\
\hline Arquiteto & 3 \\
\hline Gerente de Projetos & 3 \\
\hline Movimento social & 3 \\
\hline Antropólogo & 2 \\
\hline Coordenador de Comunicação & 2 \\
\hline Empresário & 2 \\
\hline Engenheiro & 2 \\
\hline Gerente de atendimento & 2 \\
\hline Instituição de ensino & 2 \\
\hline Analista de TI & 1 \\
\hline Assessor Jurídico & 1 \\
\hline Comunicólogo & 1 \\
\hline Estudante & 1 \\
\hline Físico & 1 \\
\hline Instrutor de Cultura digital & 1 \\
\hline Museólogo & 1 \\
\hline Pesquisador & 1 \\
\hline Programador & 1 \\
\hline & \\
\hline
\end{tabular}

MCI: Marco Civil da Internet; TI: tecnologia da informação.

Tabela 4. Representação percentual das principais vozes especializadas

\begin{tabular}{lcc|c}
\hline Qualidade da voz & Número de tweets & \% dos $\boldsymbol{t}$ weets totais (388) & \% dos tweets na área (299) \\
\hline Twitter oficial do $\mathrm{MCl}$ & 51 & $13 \%$ & $17 \%$ \\
\hline Mídia horizontal & 42 & $11 \%$ & $14 \%$ \\
\hline Ciberativista & 29 & $8 \%$ & $10 \%$ \\
\hline Organização social & 26 & $7 \%$ & $9 \%$ \\
\hline Professor & 23 & $6 \%$ & $8 \%$ \\
\hline Ativista & 20 & $5 \%$ & $6 \%$ \\
\hline Analista de sistemas & 18 & $5 \%$ & $5 \%$ \\
\hline Empreendedor & 15 & $4 \%$ & $4 \%$ \\
\hline Jornalista & 13 & $3 \%$ & $3 \%$ \\
\hline Mídia vertical & 10 & $3 \%$ & $7 \%$ \\
\hline
\end{tabular}

$\mathrm{MCl}$ : Marco Civil da Internet. 
das principais vozes especializadas no debate, dentro do universo de postagens da categoria e dentro do universo total de tweets.

Se deslizarmos da noção de especialista para a de usuário único, para testarmos ainda mais quão plural foi a discussão, percebemos que 73 usuários únicos especializados dialogaram sobre o tema Marco Civil da Internet no Twitter. No entanto, houve, novamente, uma grande repetição de vozes: dez usuários, juntos, responderam por $46 \%$ das postagens totais ( 178 de 388 tweets) e 60\% das postagens na categoria (178 de 299 tweets). Na Tabela 5, estão dispostos os usuários únicos especializados com maior percentual de postagens durante o debate.

Já no caso das vozes não especializadas, o número de tweets por usuários únicos foi melhor distribuído: no total, participaram da discussão, 36 usuários não especialistas, dentre os quais os dez perfis mais falantes foram responsáveis por $42 \%$ das postagens dentro do universo da categoria (ou 21 tweets em 48) e 5\% das postagens totais (21 em 388 tweets). Na Tabela 6, estão dispostos os usuários únicos não especializados no tema com maior percentual de postagens durante o debate:

No caso de usuários sem definição possível (NDA), dialogaram sobre o tema 27 diferentes perfis, dentro do universo de 41 tweets postados por esta categoria. Os dez usuários únicos mais falantes foram responsáveis por 24 (ou 59\% das postagens) dentro da categoria e $6 \%$ dentro do universo total de tweets. Na Tabela 7, estão dispostos os usuários únicos sem definição de posição social e organizacional possível com maior percentual de postagens durante o debate.

Somando os usuários únicos das três categorias (vozes especializadas, não especializadas e NDA), obtivemos um total de 136 diferentes perfis participantes do debate.

Tabela 5. Usuários únicos especializados com maior percentual de postagens

\begin{tabular}{l|c|c|c|c} 
Posição social & Usuário & Tweets & \% dos tweets totais (388) & \% dos tweets na área (299) \\
\hline Twitter oficial MCl & @usuário1 & 51 & $13 \%$ & $17 \%$ \\
\hline Mídia horizontal & @usuário2 & 39 & $10 \%$ & $13 \%$ \\
\hline Ciberativista & @usuário3 & 20 & $5 \%$ & $7 \%$ \\
\hline Analista de sistemas & @usuário4 & 16 & $4 \%$ & $5 \%$ \\
\hline Organização social & @usuário5 & 12 & $3 \%$ & $4 \%$ \\
\hline Ativista & @usuário6 & 11 & $2 \%$ & $4 \%$ \\
\hline Mídia vertical & @usuário7 & 10 & $2 \%$ & $2 \%$ \\
\hline Organização social & @usuário8 & 7 & $2 \%$ & $2 \%$ \\
\hline Empreendedor & @usuário9 & 6 & $2 \%$ & $2 \%$ \\
\hline Empreendedor & @usuário10 & 6 & $2 \%$ & \\
\hline
\end{tabular}

$\mathrm{MCl}$ : Marco Civil da Internet. 
Tabela 6. Usuários únicos não especializados com maior percentual de postagens

\begin{tabular}{l|c|c|c|c}
\hline Posição social & Usuário & Tweets & \% dos tweets totais (388) & \% dos tweets na área (48) \\
\hline Mídia Horizontal & @usuário11 & 3 & $1 \%$ & $6 \%$ \\
\hline Mídia Horizontal & @usuário12 & 3 & $1 \%$ & $6 \%$ \\
\hline Pesquisador & @usuário13 & 3 & $1 \%$ & $6 \%$ \\
\hline Cantor & @usuário14 & 2 & $1 \%$ & $4 \%$ \\
\hline Empresa privada & @usuário15 & 2 & $1 \%$ & $4 \%$ \\
\hline Partido & @usuário16 & 2 & $1 \%$ & $4 \%$ \\
\hline Professor & @usuário17 & 2 & $1 \%$ & $4 \%$ \\
\hline Advogado & @usuário18 & 1 & $1 \%$ & $2 \%$ \\
\hline Analista de comunicação & @usuário19 & 1 & $1 \%$ & $2 \%$ \\
\hline Assessor de comunicação & @usuário20 & 1 & $1 \%$ & $2 \%$
\end{tabular}

Tabela 7. Usuários únicos indefinidos com maior percentual de postagens

\begin{tabular}{lccccc}
\hline Posição social & Usuário & Tweets & \% dos tweets totais (388) & \% dos tweets na área (41) \\
\hline Usuário indefinido & @usuário21 & 4 & $1,00 \%$ & $10 \%$ \\
\hline Usuário indefinido & @usuário22 & 3 & $1,00 \%$ & $7 \%$ \\
\hline Usuário indefinido & @usuário23 & 3 & $1,00 \%$ & $7 \%$ \\
\hline Usuário indefinido & @usuário24 & 3 & $1,00 \%$ & $7 \%$ \\
\hline Usuário indefinido & @usuário25 & 2 & $0,50 \%$ & $5 \%$ \\
\hline Usuário indefinido & @usuário26 & 2 & $0,50 \%$ & $5 \%$ \\
\hline Usuário indefinido & @usuário27 & 2 & $0,50 \%$ & $5 \%$ \\
\hline Usuário indefinido & @usuário28 & 2 & $0,50 \%$ & $5 \%$ \\
\hline Usuário indefinido & @usuário29 & 2 & $0,50 \%$ & $2 \%$ \\
\hline Usuário indefinido & @usuário30 & 1 & $0,20 \%$ & \\
\hline
\end{tabular}

Sobre as mídias e os temas referidos, de um total de 388 tweets, 125 tiveram mídias mais horizontais incluídas; 6 utilizaram mídias mais verticais; 180 não fizeram referência a nenhuma mídia; e em 77 casos o link disponibilizado já não estava mais disponível na Web. Em termos percentuais, em 32\% das postagens foram compartilhados links de mídias horizontais; em 2\%, de mídias verticais; em 20\% o link de referência já não estava mais disponível na $W e b$; e em $46 \%$ dos posts totais não havia referência a nenhuma mídia, conforme disposto no Gráfico 2.

Traçando um comparativo entre a mídia compartilhada e o conhecimento dos usuários no tema, obtivemos os resultados dispostos no Gráfico 3.

Houve, portanto, um grande compartilhamento de conteúdo criado por mídias mais horizontais e um baixo número de links referentes às mídias mais verticais. Entre os fatores que podem ter contribuído para isso estão o grande número de compartilhamento do site do Marco Civil da Internet, local onde foi realizada a Consulta Pública e onde eram disponibilizadas 


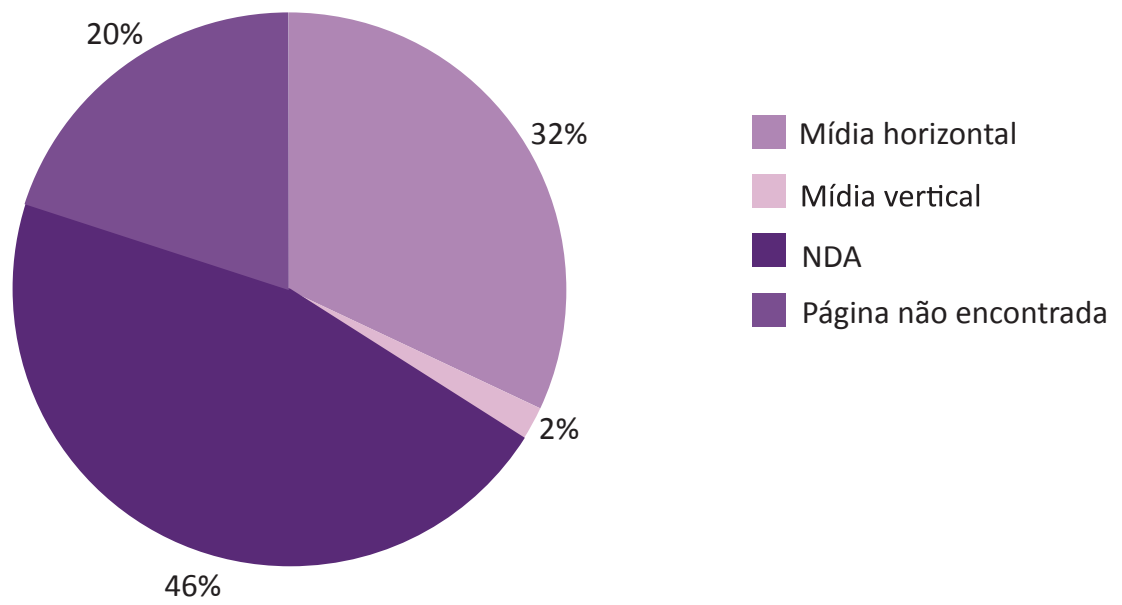

Gráfico 2. Compartilhamento de mídias

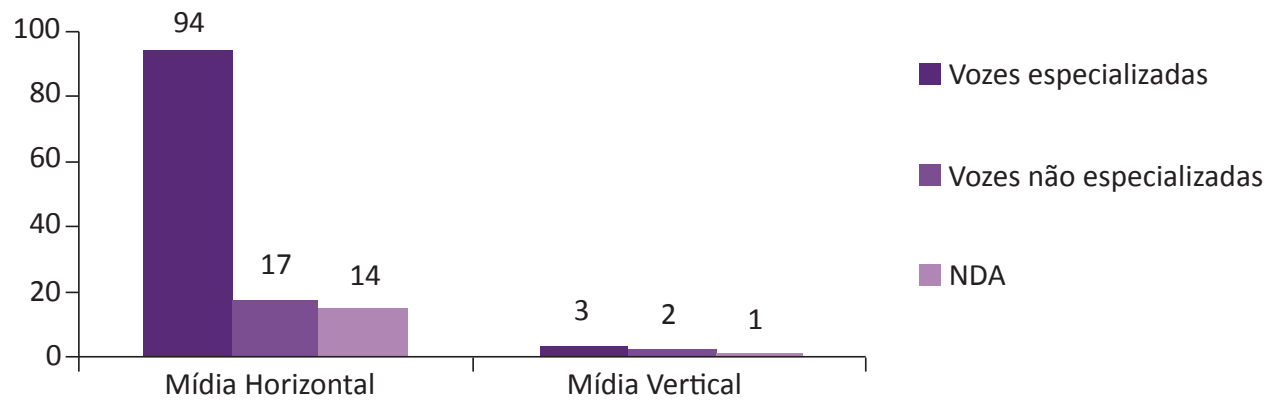

Gráfico 3. Compartilhamento de mídias versus grau de especialização

as principais informações sobre o tema, e de sites de Organizações Sociais em prol de uma internet livre. Além disso, pode ter contribuído para a escassez de links de mídias verticais a possível falta de noticiamento sobre o Marco Civil da Internet pela grande mídia, ideia bastante difundida e comentada pelos usuários presentes no debate. Sobre a relação estabelecida entre os links compartilhados e a afinidade do usuário com a área, os usuários com conhecimento na temática fizeram uso com maior recorrência das referências midiáticas, o que talvez denote um maior grau de informação e localização dos espaços de discussão por estes perfis.

Sobre os principais temas compartilhados, listamos os dez com maior quantidade de postagens, que corresponderam a 54\% (ou 209) das 388 postagens totais. Dentro do período estipulado, os usuários abordaram, principalmente, as temáticas expostas na Tabela 8.

No dia 29 de outubro de 2009, dia de abertura da Primeira Consulta Pública, ocorreu o lançamento do Marco Civil da Internet, evento realizado na FGV do Rio de Janeiro e 
Tabela 8. Principais temas compartilhados

\begin{tabular}{l|c|c|c} 
Tema & Total & $\begin{array}{c}\text { \% dos } \\
\text { tweets } \\
\text { totais (388) }\end{array}$ & $\begin{array}{c}\text { \% na soma dos 10 temas mais } \\
\text { compartilhados (209) }\end{array}$ \\
\hline Transmissão do evento de lançamento do $\mathrm{MCl}$ & 54 & $14 \%$ & $26 \%$ \\
\hline Evento de lançamento do $\mathrm{MCl}$ & 51 & $13 \%$ & $24 \%$ \\
\hline Chamada para participação no $\mathrm{MCl}$ & 29 & $7 \%$ & $14 \%$ \\
\hline O criador da ideia de um MCl & 13 & $3 \%$ & $6 \%$ \\
\hline Início da construção colaborativa do MCl & 12 & $3 \%$ & $5 \%$ \\
\hline Explicações sobre o MCl & 11 & $3 \%$ & $5 \%$ \\
\hline Grupo oficial de discussão do MCl & 11 & $3 \%$ & $5 \%$ \\
\hline Followfriday & 11 & $3 \%$ & $4 \%$ \\
\hline Blog do MCl & 9 & $2 \%$ & $4 \%$ \\
\hline PL do Azeredo & 8 & $2 \%$ & \\
\hline
\end{tabular}

MCl: Marco Civil da Internet; PL: Projeto de Lei.

bastante compartilhado entre os usuários, que tanto indicavam o link de transmissão do evento para acompanhamento em tempo real, quanto faziam a cobertura dos acontecimentos no local. Além disso, houve uma forte corrente de mobilização de internautas, na tentativa de divulgar a abertura da Consulta Pública, o Twitter oficial do Marco Civil e o endereço eletrônico onde os grupos de discussão podiam opinar e participar da construção de um Marco Civil para a internet. Também foi pauta da discussão o Projeto de Lei apresentado pelo deputado Eduardo Azeredo (PSDB), bastante criticado na Web por internautas, que apontavam o projeto de um Marco Civil para a Internet como uma resposta a este "AI5 Digital", nomenclatura dada pelos próprios usuários à proposta.

Relacionando os temas compartilhados à especialização dos usuários em relação ao assunto, percebemos que os temas mais compartilhados pelos especialistas na área tiveram relação com o evento de lançamento do Marco Civil da Internet, que ocorreu na FGV, Rio de Janeiro. Houve, também, uma forte mobilização para a participação dos usuários em geral na discussão sobre a criação de um Marco Civil para a internet. Neste recorte, o tema "PL do Azeredo" deu lugar à “Cobertura do Lançamento do Marco Civil da Internet”, como mostra a Tabela 9.

Entre os não especialistas, dos os dez temas mais compartilhados, permaneceram presentes o evento de lançamento do Marco Civil da Internet e a mobilização para a participação dos usuários na construção do Marco Civil. Os temas "Cobertura do lançamento do Marco Civil da Internet" e "Divulgação do blog do Marco Civil da Internet" deram lugar ao "PL do Azeredo" e "Divulgação do Twitter do Marco Civil da Internet", conforme é demonstrado na Tabela 10. 
Tabela 9. Temas versus vozes especializadas

\begin{tabular}{l|c|c|c} 
Tema x Especialistas & $\begin{array}{c}\text { Tweets } \\
\text { especialistas }\end{array}$ & $\begin{array}{c}\text { Tweets } \\
\text { totais }\end{array}$ & $\begin{array}{c}\text { \% dos tweets de especialistas na } \\
\text { quantidade total do tema }\end{array}$ \\
\hline Evento de lançamento do $\mathrm{MCl}$ & 48 & 51 & $94 \%$ \\
\hline Transmissão do evento de lançamento do $\mathrm{MCl}$ & 34 & 54 & $63 \%$ \\
\hline Chamada para participação no $\mathrm{MCl}$ & 24 & 29 & $82 \%$ \\
\hline O criador da ideia de um MCl & 11 & 13 & $85 \%$ \\
\hline Grupo oficial de discussão do MCl & 10 & 11 & $91 \%$ \\
\hline Followfriday & 10 & 11 & $91 \%$ \\
\hline Início da construção colaborativa do $\mathrm{MCl}$ & 9 & 12 & $75 \%$ \\
\hline Explicações sobre o MCl & 8 & 11 & $73 \%$ \\
\hline Divulgação do blog do MC & 8 & 9 & $89 \%$ \\
\hline Cobertura do lançamento do $\mathrm{MCl}$ & 6 & 7 & $86 \%$ \\
\hline
\end{tabular}

MCl: Marco Civil da Internet; PL: Projeto de Lei.

Tabela 10. Temas versus vozes não especializadas

\begin{tabular}{l|c|c|c} 
Tema X não especialistas & $\begin{array}{c}\text { Tweets não } \\
\text { especialistas }\end{array}$ & $\begin{array}{c}\text { Tweets } \\
\text { totais }\end{array}$ & $\begin{array}{c}\text { \% dos tweets de não especialistas } \\
\text { na quantidade total }\end{array}$ \\
\hline Transmissão do evento de lançamento do $\mathrm{MCl}$ & 15 & 54 & $28 \%$ \\
\hline Evento de lançamento do $\mathrm{MCl}$ & 3 & 51 & $6 \%$ \\
\hline Chamada para participação no $\mathrm{MCl}$ & 3 & 29 & $10 \%$ \\
\hline O criador da ideia de um MCl & 2 & 13 & $15 \%$ \\
\hline Início da construção colaborativa do MCl & 2 & 12 & $17 \%$ \\
\hline PL do Azeredo & 2 & 8 & $14 \%$ \\
\hline Divulgação do Twitter do MCl & 1 & 7 & $9 \%$ \\
\hline Grupo oficial de discussão do MCl & 1 & 11 & $9 \%$ \\
\hline Followfriday & 1 & 11 & $9 \%$ \\
\hline Explicações sobre o MCl & 1 & 11 & \\
\hline
\end{tabular}

MCI: Marco Civil da Internet; PL: Projeto de Lei.

\section{Considerações finais}

Nossas hipóteses, antes de iniciar a pesquisa, eram a de que a Web traria uma diversidade relativa de fontes ao debate e de que a discussão no Twitter traria uma contribuição da mídia mais horizontal, não em relação aos temas, mas às vozes presentes na "conversa".

A primeira delas se confirmou: embora fique nítida a repetição de determinadas fontes, vimos, no debate, a participação de usuários de diversas áreas, o que pode contribuir para uma visão mais abrangente do tema. É preciso ressaltar, porém, que houve uma predominância de vozes especializadas no tema, que representaram $77 \%$ das postagens 
totais, talvez pela especificidade, complexidade e novidade do Marco Civil da Internet. Esse aspecto nos leva a sugerir um possível problema representacional no espaço analisado no que diz respeito à desigualdade de acesso e de consideração sobre o tema. Porém, ainda que no caso analisado a discussão não tenha sido tão plural quanto parte da teoria imagina ou deseja, é preciso considerar o contexto informacional que envolveu o tema, isto é, o grau de informação disponível para que os usuários pudessem se inteirar sobre o assunto e, então, participar do debate. No entanto, para medir o grau de publicização do tema e estabelecer uma correlação com os resultados obtidos nesta pesquisa, seria necessário realizar outro estudo.

Sobre a quantidade de usuários únicos, houve pouca variedade de perfis dialogando, se considerarmos que a consulta pública sobre o Marco Civil da Internet era aberta a todos os interessados, e uma grande repetição de vozes, ou seja, um alto número de postagens concentradas em poucas pessoas, situação recorrente durante o período analisado. Sampaio et al. (2013) e Bragatto et al. (2015) já haviam chegado a conclusões semelhantes em análises conjuntas realizadas no fórum online que hospedou a consulta pública do Marco Civil da Internet. De acordo com os autores, a discussão realizada na ferramenta mencionada foi limitada, no que diz respeito à adesão e ao pluralismo de vozes. Houve alta concentração de mensagens postadas por um baixo número de usuários, que eram, em sua maioria, indivíduos com alto interesse na questão e com algum conhecimento na área. Vale ressaltar que alguns estudos relativizam e destacam aspectos positivos na participação de superposters2 durante os debates virtuais (GRAHAM; WRIGHT, 2013; ALBRECHT, 2006).

Apesar da discrepância na representação das vozes especializadas, que predominaram durante o debate, e as não especializadas, responsáveis por uma parcela pequena das postagens, as temáticas abordadas pelos dois grupos manteve-se similar: ambos abordaram o evento de lançamento do Marco Civil da Internet, realizado pela FGV, e conclamaram os usuários em geral a participarem da Consulta Pública para a construção deste Marco Civil.

\footnotetext{
Graham e Wright (2013) ressaltam que determinados estudos apontam para a concentração de participação e a consequente falta de igualdade nos debates online, enquadrando a superparticipação de forma negativa. Para os autores, é necessário analisar de forma mais contundente a participação de superposters, isto é, participantes com postagens frequentes em fóruns de discussão, problematizando os aspectos positivos que este tipo de participação pode trazer para o debate.
} 
As mídias mais horizontais, que compõem a nossa segunda hipótese, estiveram muito presentes no debate como fonte primária, ou seja, pela postagem de tweets, e como fonte de referência em postagens de outros usuários. Houve um expressivo número de compartilhamento de links deste tipo de mídia, aspecto que pode ser em parte explicado pelo fato de que grande parte dos tweets indicavam o site do Marco Civil da Internet, ambiente em que as discussões e as consultas foram feitas. Além disso, houve um grande movimento de organizações sociais em prol de uma internet livre que realizavam muitas postagens em seus blogs e sites e as difundiam no Twitter. Já o compartilhamento de mídias verticais não foi expressivo, talvez por um fraco espaço disponibilizado por este tipo de mídia ao assunto no período da primeira consulta pública. Em relação ao cruzamento entre compartilhamento de mídias e especialização na área, no geral, os usuários especialistas realizaram um debate mais referenciado do que os não especialistas.

Sobre os temas, no debate estabelecido no Twitter predominaram as postagens que abordaram o evento de lançamento do Marco Civil da Internet, bem como o início da primeira consulta pública, ficando de fora as polêmicas que envolviam o assunto, assim como a discussão sobre o teor e as diretrizes que um marco civil para a internet deveria conter. O recorte estabelecido pode ter interferido nesses resultados, sendo necessário realizar uma coleta mais ampla dos tweets, talvez durante todo o período da primeira consulta pública, a fim de verificar se o diálogo englobou estes aspectos.

Uma das dificuldades encontradas durante a pesquisa, talvez pelo recorte temporal tão distante, foi a indisponibilidade de muitos links compartilhados. Em muitos casos, ao tentarmos acessar o endereço online, a página já não existia mais ou o link curto era redirecionado para outra matéria.

Ainda que a discussão em torno do Marco Civil da Internet, no período estipulado, não tenha trazido uma contribuição expressiva e representativa de grande parte da sociedade, o debate no Twitter pode ser considerado positivo, no que diz respeito à contribuição das Mídias Horizontais, que dominaram o espaço de visibilidade naquele momento. Além disso, mesmo que a discussão tenha ficado mais restrita às vozes especialistas, os mesmos podem ter sido referências informativas e divulgadoras do tema para os usuários em geral. 


\section{Referências}

ALBRECHT, Steffen. Whose voice is heard in online deliberation? Information, Deliberation \& Society, v. 9, n. 1, p. 62-82, 2006.

BENKLER, Yochai. The wealth of networks: how social production transform markets and freedom. New Haven e Londres: Yale University Press, 2006.

BOHMAN, James. Expanding dialogue: The Internet, the public sphere and prospects for transnational democracy. The Sociological Review, v. 52, p. 131-155, 2004.

BRAGATTO, Rachel C.; SAMPAIO, Rafael C.; NICOLAS, Maria A. O Marco Civil da Internet: como foi construído, quem participou e quais os impactos. Trabalho apresentado no V Seminário Nacional Sociologia \& Política, de 14 a 16 de maio de 2014, Curitiba. Disponível em: $<$ http://www.humanas.ufpr.br/portal/seminariosociologiapolitica/ files/2014/08/24778_1397848930.pdf>. Acesso em: 18 mar. 2015.

CASTELLS, Manuel. A Galáxia da internet: reflexões sobre a internet, os negócios e a sociedade. Rio de Janeiro: Jorge Zahar, 2003.

CHADWICK, Andrew. Web 2.0: New Challenges for the Study of E-Democracy in an Era of Informational Exuberance. Journal of Law and Policy for the Information Society, v. 5, n. 1, p. 9-41, 2009.

CAREY, James. Communication as Culture. Nova York: Routledge, 1989.

DAHLGREN, Peter. The Internet, Public Spheres, and Political Communication: Dispersion and Deliberation. Political Communication, v. 22, n. 2, p. 147-162, 2005.

FRASER, Nancy. Transnationalizing the public sphere: On the legitimacy and efficacy of public opinion in a post-westphalian world. Theory, Culture \& Society, v. 24, n. 4, p. 7-30, 2007.

GERHARDS, Jürgen; SCHAFER, Mike S. Is the internet a better public sphere? Comparing old and new media in the USA and Germany. New Media \& Society, v. 12, n. 1, p. 143$160,2010$.

GOLDBERG, Greg. Rethinking the Public/Virtual Sphere: The Problem with Participation. New Media and Society, v. 13, n. 5, p. 739-754, 2011.

GOMES, Wilson. Internet e participação política. Comunicação e democracia. São Paulo: Paulus, 2008.

GOMES, Wilson; MAIA, Rousiley C. M. Comunicação e democracia. São Paulo: Paulus, 2008. 
GRAHAM, Todd, WRIGHT, Scott. Discursive equality and everyday talk online: the impact of "Superparticipants". Journal of Computer-Mediated Communication, vol. 19, p. 625-642, 2013.

ITUASSU, A.; LIFSCHITZ, S. Opinião Pública e Comunicação política em \#ELEIÇÕES2014: uma análise preliminar. Disponível em: $<$ http://compos.org.br/biblioteca/final_ comautoria_2782.pdf $>$. Acesso em: 19 jun. 2015.

MAIA, Rousiley C. M. Democracia e a Internet como esfera pública virtual: aproximação às condições da deliberação. In: GOMES, Wilson; MAIA, Rousiley C. M. Comunicação e democracia. São Paulo: Paulus, 2008.

MARQUES, Francisco P. J. A.; SILVA, Fernando W. O.; MATOS, Nina R. Estratégias de comunicação política online: Uma análise do perfil de José Serra no Twitter. In: MARQUES, Francisco P. J. A.; SAMPAIO, Rafael C.; AGGIO, Camilo. (Orgs.). Do clique à urna: Internet, redes sociais e eleições no Brasil. Salvador: EDUFBA, 2013.

NEUMAN, W. L. The impact of the New Media. In: BENNETT, W. L.; ENTMAN, Robert M. Mediated Politics: Communication in the Future of Democracy. Cambridge: Cambridge University Press, 2001, p. 299-322.

SAMPAIO, Rafael C.; MAIA, Rousiley C. M.; MARQUES, Francisco P. J. A. Participação e deliberação na internet: Um estudo de caso do Orçamento Participativo Digital de Belo Horizonte. Opinião Pública, v. 16, n. 2, p. 446-477, 2010. Disponível em: http://www. scielo.br/scielo.php?script=sci_arttext\&pid=S0104-62762010000200007\&lng=pt\&nrm= iso\&tlng=pt. Acesso em: 24 set. 2015.

SAMPAIO, Rafael C.; BARROS, Samuel A. R.; MORAIS, Ricardo. Como avaliar a deliberação online? Um mapeamento de critérios relevantes. Opinião Publica, v. 18, n. 2, p. 470-489, 2012.

SAMPAIO, Rafael C.; BRAGATTO, Rachel C.; NICOLÁS, Maria A. Inovadora e democrática. Mas e aí? Uma análise da primeira fase de consulta online sobre o Marco Civil da Internet. Trabalho apresentado no V Congresso da Compolitica, de 08 a 10 de maio de 2013 em Curitiba. Disponível em: <http:/www.compolitica.org/home/wp-content/ uploads/2013/05/GT-04-\%C3\%94\%C3\%87\%C3\%B4-Internet-e-Pol $\pm \% C 2 \% A 1$ tica-RafaelCardoso-Sampaio.pdf $\geq$. Acesso em: 27 mar. 2015.

SHAW, Donald; Hamm, Bradley J.; TERRY, Thomas C. Vertical Versus Horizontal Media: Using Agenda-setting and Audience Agenda-melding to Create Public Information Strategies in The Emerging Papyrus Society. Military Review, November-December, p. 13-25, 2006. 